\title{
Circo e educação: uma experiência de prática circense no espaço escolar
}

\author{
Alberto Carlos de Souza \\ Universidad Nacional Rosario - Argentina \\ albertocarlos_souza@hotmail.com
}

\section{Resumo}

Foi realizada uma oficina de cultura de resistência com 27 crianças de 10 anos de idade, estudantes de uma escola pública municipal de Vitória - ES, a qual teve como propósito celebrar o Dia Internacional do Circo, em 27 de março. Toda a produção estética dessa oficina girou em torno da música "Circo Marimbondo", de autoria de Milton Nascimento e Fernando Brant (1978), e contou com a elaboração de pictografias de artistas circenses (desenho com massa de modelar), a partir da seguinte questão norteadora: "Quem são esses marimbondos, de quem tanto fala a música?". Os marimbondos foram representados pelas crianças principalmente como figura, artistas fantásticos: palhaços, bailarinas, homem-bala, trapezista, mulher barbada e mulher gorila. A oficina culminou com a apresentação de toda a produção estética para a família daquelas crianças.

Palavras-chave: Cultura. Educação. Diversidade cultural. Circo. Música popular brasileira.

\section{Abstract}

\section{Circus and education: a practical experiences in the school space}

Workshop by culture of resistance carried out with 27 children from 10 years old, students at a local public school in Vitória - ES, which aimed to celebrate the International Day Circus on March 27. All the aesthetic production of the workshop revolved around the song Circus Wasp, by Milton Nascimento and Fernando Brant (1978) and consisted elaboration of pictography of circus artists (drawing with clay modeling ), from question: "Who are these wasps whose music speaks so much?" The wasps were represented mainly by children like it features amazing artists as: clowns, dancers, man bullet, trapeze artists, and bearded woman or female gorilla. The workshop culminated with the presentation of the whole aesthetic production to the family of those children.

Keywords: Culture. Education. Cultural diversity. Circus. Brazilian popular music. 


\section{INTRODUÇÃO}

Este estudo pretende relatar as representações sociais que um grupo de 27 crianças de nove anos de idade, estudantes do $5^{\circ}$ ano da Escola Municipal de Ensino Fundamental Prof. Vercenílio da Silva Pascoal, no município de Vitória/ES, tem sobre o circo como espaço cultural. Tal estudo constituiu-se como a primeira parte do projeto Circo na Escola, idealizado pelo professor de arte Alberto Carlos de Souza, que teve como motivação criar um espaço estético para discussão, em nossa escola, do circo como lugar de cultura, pois é preciso resgatar esse espaço singular que ele representa na contemporaneidade, como um lugar de fantasia. De fato, quando os artistas do "Circo Royal", que estava na cidade de Vitória/ES, estendem a lona azul, o cotidiano das crianças muda, pois, para elas, o circo é um ambiente mágico e fantástico.

Para Hall (2006), na modernidade reflexiva em que vivemos, o homem, diferentemente da concepção iluminista ou sociológica, é um sujeito descentrado que vive em crise de identidade, visto que as velhas identidades estão continuamente sendo substituídas por novas identidades. Nessa perspectiva, o autor parte de três concepções de sujeitos construídos e assumidos ao longo do processo histórico que determina as identidades, a saber:

- O sujeito iluminista: aquele que era centrado, possuindo uma concepção individualizada na qual o centro essencial do "Eu" correspondia à sua identidade.

- O sujeito sociológico: aquele que rompeu com tal concepção individualizada à medida que passou por transformações de ideias e de pensamentos, a partir das quais começou a interagir com a sociedade.

- O sujeito pós-moderno: aquele que faz ruptura com a concepção sociológica, quando é perturbado por mudanças estruturadas e institucionais, assumindo identidades diferentes em diferentes momentos, pois, para as mesmas crianças, o circo perdeu sua identidade; elas (c) (1) Esta obra está licenciada sob uma Licença Creative Commons. 
queriam ver vários animais, como leões, tigres, macacos, zebras, e os artistas circenses, como os palhaços, domadores, etc.

Há de se considerar, ainda, que, na concepção pedagógica atual, existe uma indissolubilidade entre educação e cultura,

[...] porque a educação como formação e instrumento de participação precisa partir das potencialidades do educando e motivá-lo à criatividade própria. A cultura constitui o contexto próprio da educação, porque é motivação fundamental para a mobilização comunitária e quadro concreto da criatividade histórica. (DEMO, 1993, p. 58).

A LDB prescreve que, entre outros conhecimentos, o ensino de Arte, Cultura e História constitui componentes curriculares obrigatórios nos diversos níveis da educação fundamental; dessa forma, possibilita a promoção da consciência e o desenvolvimento cultural (local e universal) dos alunos. De acordo com a referida lei, o ensino deverá valorizar a experiência extracurricular dos educandos, e foi nessa perspectiva que se inseriu esse processo interdisciplinar que foi viabilizado por essas disciplinas, nas quais esses alunos das duas turmas da oitava série da referida escola estavam matriculados. O circo (re)nasce com o envolvimento dos alunos e nas disciplinas Educação Artística e História, estando em concordância com as recomendações dos Parâmetros Curriculares Nacionais (PCNs), uma vez que:

[...] é fundamental que a escola assuma a valorização da cultura de seu próprio grupo, $[\ldots]$ propiciando às crianças e aos jovens pertencentes aos diferentes grupos sociais o acesso ao saber, tanto no que diz respeito aos conhecimentos socialmente relevantes da cultura brasileira no âmbito nacional e regional como no que faz parte do patrimônio universal da humanidade. (BRASIL, 1998, p. 44).

Nesse espaço de tempo, Milton Nascimento, agora com o Ronaldo Bastos, continua falando de circo. Um outro circo, o circo humano, um circo contemporâneo no qual o palhaço corre um risco que pode ser simbólico ou real: 
Às vezes o risco é símbolico (a queda da bola do malabarista ou ainda o comportamento desequilibrado do clown), mas o risco que se corre na cena é, na maior parte do tempo, real e vital, colocando em causa a integridade física do artista. A vida é colocada em jogo na cena, e a morte - para ser julgada? - é verdadeira e frequentemente convocada. (GOUDARD, 2009, p. 25, grifo nosso).

Sobre esse relato, especificamente, tratou-se de um projeto implementado à luz dos Parâmetros Curriculares Nacionais (PCNs), um documento editado pelo Ministério da Educação que oferece as balizas para se construir uma referência curricular nacional para o ensino fundamental. Entre as suas muitas recomendações, tais parâmetros recomendam aos educadores que

[...] as crianças e os jovens deste país desenvolvam suas diferentes capacidades, enfatizando que a apropriação dos conhecimentos socialmente elaborados é base para a construção da cidadania e da sua identidade, e que todos são capazes de aprender e mostrar que a escola deve proporcionar ambientes de construção dos seus conhecimentos e de desenvolvimento de suas inteligências, com suas múltiplas competências [...] (BRASIL, 1998, p. 10-11).

Tais PCNs prescrevem também que os temas sociais urgentes, chamados Temas Transversais, devam ser desenvolvidos de maneira interdisciplinar no ensino fundamental (BRASIL, 1998).

De acordo com os referidos PCNs, é necessário que os docentes atuem com a diversidade existente entre os alunos e que os seus conhecimentos prévios sirvam como fonte de aprendizagem de convívio social e não apenas como um meio de aprendizagem de conteúdos específicos (BRASIL, 1998).

A respeito de cultura, Laraia (2005) conclui que

[...] cada sistema cultural está sempre em mudança. Entender essa dinâmica é importante para atenuar o choque entre as gerações e evitar comportamentos preconceituosos; da mesma forma que é fundamental para a humanidade a compreensão das diferenças entre povos de culturas diferentes, é necessário saber entender as diferenças que ocorrem dentro do mesmo sistema. (LARAIA, 2005, p. $101)$.

Assim posto, entendemos que as questões afeitas às relações ao circo, aqui incluídos os atores e a sua relação com o trabalho, constituem um tema social urgente. Como forma de celebrar o Dia do Circo na escola, propusemos este projeto interdisciplinar de protagonização 
das crianças, deixando emergir suas representações sobre o circo como lugar de resistência cultural.

Conforme observam Cheire e Bulir (2001), as representações são construções simbólicas que norteiam as atividades. Tais representações são elaboradas coletiva e socialmente pelos atores sociais e servem para eles nomearem, apreenderem e transformarem o seu meio ambiente. Essas representações circulam e transformam-se principalmente por meio das relações de comunicação desenvolvidas entre os atores sociais.

Sobre as representações sociais, uma forma de conhecimento prático que se insere muito bem entre as correntes que estudam o senso comum, Moscovici (1978, p. 26) as define como "[...] uma modalidade de conhecimento particular que tem por função a elaboração de comportamentos e a comunicação entre os indivíduos", visto que constituem “[...] um corpus organizado de conhecimentos e uma das atividades psíquicas graças às quais os homens fazem inteligível a realidade física e social, integram-se em um grupo ou em uma relação cotidiana de intercâmbios, liberam os poderes de sua imaginação.” (Moscovici, 1978, p. 28).

$\mathrm{Na}$ elaboração do referido projeto, o nosso propósito foi o de deixar emergir as representações que as crianças, enquanto atores sociais cheios de conhecimentos prévios, tinham sobre o circo. Para tal, nos apropriamos da música "Circo Marimbondo”, de autoria de Nascimento e Bastos (1976), como ponto de partida da nossa intervenção, por entendermos que essa letra é um hino de amor a todos que fazem parte do circo, (in)comuns brasileiros, que, assim como aqueles profissionais circenses que fazem de seu trabalho uma promoção da cultura, ainda lutam por fazer valer os seus direitos e participam da construção do nosso cotidiano social.

No campo da música, Adorno considera que ela, embora semelhante, não é uma linguagem, pois não possui um sistema de signos: 
A música assemelha-se com a linguagem na qualidade de sequência temporal de sons articulados, que são mais do que meros sons. Eles dizem algo, frequentemente algo humano. Dizem tão mais enfaticamente, quanto mais à maneira elevada estiver a música. A sequência de sons converteu-se em lógica: existe certo e errado. Porém, aquilo que foi dito não pode se depreender da música. Ela não compõe nenhum sistema de signos. (ADORNO, 2008, p. 1).

Apoiados pela musicalidade da interpretação de "Circo Marimbondo", num dueto nas vozes de Milton Nascimento e Clementina de Jesus, buscamos, através do desenvolvimento da tensão psíquica das crianças, dar visibilidade às representações que elas têm sobre o circo. Utilizamos para tanto a linguagem estética, compreendida pela sua dimensão plástica e musical.

Sobre o conceito de tensão psíquica, tão essencial ao processo de criação, Ostrower (1987) observa que

[...] criar não representa um relaxamento ou um esvaziamento pessoal, nem uma substituição imaginativa da realidade; criar representa uma intensificação do viver, um vivenciar-se no fazer; e, em vez de substituir a realidade, é a realidade; é uma realidade nova que adquire dimensões novas pelo fato de nos articularmos, em nós e perante nós mesmos, em níveis de consciência mais elevados e mais complexos. Somos, nós, a realidade nova. Daí o sentimento do essencial e necessário no criar, o sentimento de um crescimento interior, em que nos ampliamos em nossa abertura para a vida. (OSTROWER, 1987, p. 27-28).

O ponto de partida do projeto foi o alcance do seguinte objetivo: conhecer as representações sociais que crianças têm sobre o circo enquanto cultura de resistência, tendo como referência a música "Circo marimbondo", de Milton Nascimento e Ronaldo Bastos (1976).

A letra da música "Circo Marimbondo" (NASCIMENTO; BASTOS, 1976) é composta como: 


\author{
CIRCO MARIMBONDO \\ Circo Marimbondo \\ Circo Marambaia \\ Eu cheguei de longe \\ Não me atrapaia \\ Vê se não me amola \\ Larga minha saia \\ Circo Marimbondo \\ Circo Marambaia \\ Se eu te der um tombo \\ Tomara que caia \\ Circo Marimbondo \\ Circo Marambaia
}

\title{
Metodologia
}

Tratou-se de uma experimentação estética de caráter histórico, plástico e musical, enquanto intervenção de ensino-aprendizagem interdisciplinar (Arte-História), na Escola Municipal de Ensino Fundamental Vercenílio da Silva Pascoal, localizada no município de Vitória.

O início da experiência foi a problematização junto aos alunos do conceito de patrimônio cultural. Segundo o artigo 216 da nossa Constituição (BRASIL, 1992, p. 120),

\footnotetext{
Constituem patrimônio cultural brasileiro os bens de natureza material e imaterial, tomados individualmente ou em conjunto, portadores de referência à identidade, à ação, à memória dos diferentes grupos formadores da sociedade brasileira, nos quais se incluem:

I - as formas de expressão;

II - os modos de criar, fazer e viver;

III - as criações científicas, artísticas e tecnológicas;

IV - as obras, objetos, documentos, edificações e demais espaços destinados às manifestações artístico-culturais;

$\mathrm{V}$ - os conjuntos urbanos e sítios de valor histórico, paisagístico, artístico, arqueológico [...] e científico.
}

A intervenção teve como cenário a EMEF Prof. Vercenílio da Silva Pascoal, da Rede Municipal de Educação de Vitória/ES. O universo dessa intervenção foi constituído pelos 25 estudantes da turma única do $3^{\circ}$ ano do ensino fundamental da referida escola.

O trabalho foi realizado através de atividades de laboratório e contou com os seguintes momentos: 
$1^{\circ}$ ) Leitura compreensiva da letra "Circo Marimbondo", buscando esclarecer termos ou expressões desconhecidas pelas crianças.

$\left.2^{\circ}\right)$ Audição silenciosa da música.

$3^{\circ}$ ) Memorização da letra da música através da escuta e canto simultâneo.

$\left.4^{\circ}\right)$ Representação do circo ou dos personagens que o integram, através da técnica de desenho com massa de modelar, a partir da seguinte questão norteadora: "Quem são esses marimbondos, de quem tanto fala a música?".

Para a elaboração do relatório dessa experimentação estética, tomamos como suporte a Análise de Conteúdo, entendida como:

[...] um conjunto de técnicas de análise das comunicações visando obter, por procedimentos sistemáticos e objetivos de descrição de conteúdo das mensagens, indicadores (quantitativos ou não) que permitam interferência de conhecimentos relativos às condições de produção/recepção (variáveis inferidas) dessas mensagens (BARDIN, 2000, p. 42).

Nem todos os fenômenos sociais são formadores de representações sociais. Uma representação social surge onde houver perigo para uma identidade coletiva e traduz a relação de um grupo com um objeto socialmente valorizado. Assim, toda representação social é a representação de algo e/ou de alguém por alguém.

Nossa opção por esse quadro teórico ficou assim justificada: a representação cultural, o circo, por um grupo de crianças. Mas, afinal, quem são essas crianças? São, conforme nos apresenta Del Priore (2006), crianças brasileiras como aquelas que estão em toda parte, com destinos variados e variados rostos: rostinhos mulatos, brancos, negros e mestiços. Algumas amadas e outras simplesmente usadas.

A partir das cenas de produção estética elaboradas por aquelas crianças, através da técnica de desenho com massa de modelar em papel branco, construímos cinco categorias analíticas, de acordo com Bardin (2000), que nos possibilitaram compreender que, para essas 
crianças, os marimbondos fazem-se representar, nesta ordem, principalmente como:

1) palhaço (7 referências);

2) bailarina (5 referências);

3) homem-bala (4 referências);

4) trapezista (4 referências);

5) mulher barbada (2 referências);

6) conga, a mulher gorila (1 referência).

Podemos evidenciar que neste estudo a representação dos artistas do circo como figura de palhaço (palhaço) ou como bailarina é a que mais se sobressai, denotando a importância da família e do lúdico na vida dessas crianças.

"Foi uma maravilha, jamais tinha ido a um circo" (Elisângela, 10 anos).

“Acho que nunca vi um lugar tão mágico e divertido como o circo" (Artur, 9 anos).

"Entrar no circo, sentar nas arquibancadas e ver os artistas foi um sonho para mim” (Bryan, 10 anos).

"Ver no palco o palhaço, o mágico, malabaristas, o globo da morte e a mulher gorila, eu jamais vou esquecer" (Bianca, 10 anos).

Dessa forma, o circo passa a fazer parte de um lugar de memória e de resistência no ambiente familiar e pode inserir a cultura de resistência para que não se extinga o circo do lúdico dessas crianças, pois é identidade cultural, tendo a família a função de propiciar cultura local de suas crianças, e os "filhos educados e esposa dedicada ao marido, às crianças e desobrigada de qualquer trabalho produtivo representavam o ideal de retidão e probidade, um tesouro social imprescindível.” (D’INCAO, 2004, p. 223).

No presente estudo, as crianças se referem aos marimbondos do circo como um personagem fantástico, geralmente inserido em ocupações pertencentes ao setor do artista: o marimbondo é palhaço, ou bailarina, ou homem-bala, ou trapezista, ou a mulher barbada, ou conga, a mulher gorila. 
A finalização do projeto se deu através de um encontro de socialização: as crianças do projeto receberam outros alunos da escola cantando em coro a canção "Circo Marimbondo". Simultaneamente, as representações elaboradas foram apresentadas no hall da referida escola.

\section{Considerações Finais}

O ponto de partida desta intervenção consistiu na exploração da musicalidade de Milton Nascimento, protagonista do movimento Clube da Esquina, que floresceu em Minas Gerais, a partir da década de 60, no auge de um dos períodos mais críticos da história contemporânea brasileira: a ditadura militar (BORGES, 1996). No conjunto da sua obra, nossa opção se deu pela música "Circo Marimbondo".

As representações sociais do circo, aqui apresentadas, são entidades quase tangíveis que "[...] circulam, cruzam-se e se cristalizam quase incessantemente, através de uma fala, um gesto, um encontro [...]” (MOSCOVICI, 1978, p. 41), no universo cotidiano dessas crianças.

O estudo evidenciou que, para essas crianças, os marimbondos se fazem representar como aquele(a) artista fantástico(a), representado(a) por Milton Nascimento, em sua infância de menino negro, filho adotivo, criança traquina, tão igual a muitas das crianças que frequentam as nossas escolas de periferia: marimbondo é palhaço, ou a bailarina, ou um homem-bala, ou trapezista, ou uma mulher barbada, ou uma mulher gorila.

\section{Referências}

BRASIL. Constituição da República Federativa do Brasil, de 5 de outubro de 1988. São Paulo: Atlas, 1992.

ADORNO, Theodor. Fragmentos sobre música e linguagem. Tradução de Manoel Dourado Bastos. Trans/Form/Ação, Marília, SP, v. 31, n. 2, 2008. Acesso em: 13 jun. 2009. Disponível em: $\quad<$ http://www.scielo.php?script=sci arttex\&pid=SO101$\underline{31732008000200010 \& \text { em\&nrm }=\text { isso }>\text {. }}$.

BARDIN, L. Análise de conteúdo. Lisboa: Edições 70, 2000. 
BORGES, M. Os sonhos não envelhecem: histórias do Clube da Esquina. São Paulo: Geração Editorial, 1996.

BRASIL. Secretaria de Educação Fundamental. Parâmetros curriculares nacionais: terceiro e quarto ciclos do ensino fundamental: introdução aos parâmetros curriculares nacionais/Secretaria de Educação Fundamental. Brasília: MEC/SEF, 1998.

DEL PRIORE, M. História das crianças no Brasil. 5. ed. São Paulo: Contexto, 2006.

DEMO, P. Participação é conquista: noções da política social participativa. 2. ed. São Paulo: Cortez, 1993.

D'INCAO, M. A. Mulher e família burguesa. In: DEL PRIORE, M. (Org.). História das mulheres no Brasil. São Paulo: Contexto, 2004.

GOUDARD, Phelippe. A estética do riso: do corpo sacrificado ao corpo abandonado. In: WALLON, Emmanuel (Org.). O circo no risco da arte. Tradução Ana Alvarenga, Augustinho de Tugny e Cristiane Lage. Belo Horizonte: Autêntica, 2009. p. 25-31.

HALL, S. Identidade cultural na pós-modernidade. Rio de Janeiro: DP\&A, 2006.

LARAIA, R. B. Cultura: um conceito antropológico. 18. ed. Rio de Janeiro: Jorge Zahar, 2005.

MOSCOVICI, S. A representação social da psicanálise. Rio de Janeiro: Zahar, 1978.

NASCIMENTO, Milton; BASTOS, Ronaldo. Circo marimbondo. In: NASCIMENTO, Milton. Geraes. Rio de Janeiro: EMI/ODEON, 1976. 1 CD. Digital. Estéreo. 61.192.473.

OSTROWER, F. Criatividade e processos de criação. 19. ed. Petrópolis: Vozes, 1987.

SCHIELE, B.; BOUCHER, L. A exposição científica: uma maneira de representar a ciência. In: JODELET, D. (Org.). As representações sociais. Rio de Janeiro: Eduerj, 2001. p. 363377. 